104 reflexions should be sensitive to changes in the c/a ratio, since one reflexion depends on the values of the $a$-axes and the other mainly on the value of the $c$-parameter. These measurements show that the c/a ratio is larger at $95^{\circ} \mathrm{K}$. than at room temperature.

As a more quantitative check, the curves shown in Fig. 1 were extrapolated to $95^{\circ} \mathrm{K}$. The values so obtained for $a$ and $c, 4.944 \mathrm{~A}$. and $13.599 \mathrm{~A}$., respectively, agree very well with the results for the 226 and $21 \cdot 10$ reflexions from the diffractometer measurements at that temperature.

I thank Dr. Donald A. Edwards for making the low-temperature measurements, and Dr. J. Samuel Smart for helpful discussions.

Selima Greenwatd

U.S. Naval Ordnance Laboratory, White Oak, Maryland.

' Greenwald, S., Nature, 168, 379 (1951).

\section{Colour Centres in Metaphosphate Glass}

IN a recent communication ${ }^{1}$, Basu states that we have attributed the coloration of metaphosphate glasses, induced by X-rays, to the activating influence of the metal (aluminium, barium, silver, ete.) in the glass, and that his results with sodium metaphosphate glasses show that ' $F$-centres' can be produced without these activators. In the references to our work cited by $\mathrm{Basu}^{2,3}$, the point is made that radiophotoluminescent centres having certain specific properties are connected with the presence of silver in potassium-barium-aluminium metaphosphate glass. It is clearly shown, we believe, in the publications from this Laboratory ${ }^{-5}$ that a visible coloration is produced upon $\mathrm{X}$-irradiation of the above silver-free base glass, two broad bands appearing with peaks at about $420 \mathrm{mu}$ and $530 \mathrm{m \mu}$. These colour centres were not attributed to any 'activating' influence of the aluminium, barium or other metallic constituents of the glass.

Solid State Division,

JAMES H. SchuLMAN

U.S. Naval Research Laboratory,

Washington 25, D.C.

1 Basu, Nature, 176, 265 (1955).

2 Schulman et al., J. App. Phys., 22, 1479 (1951).

${ }^{3}$ Schulman, NRI Memo Report 266 (1954).

- Schulman, J. Phys. Chem., 57, 749 (1953).

${ }^{5}$ Schulman et al., Nucleonics, 13, 30 (1955).

WHEN writing my communication published in Nature of August 5, I had to rely on abstracts of Mr. Schulman's papers; this was responsible for my misrepresentation of Mr. Schulman's point of view. The information now supplied by Mr. Schulman is very interesting, for it appears that none of the bands observed in my system is present in the silver-free base studied by Schulman, and his $420-\mathrm{m} \mu$ band is completely absent in my system. This shows that a more critical study of this system is necessary before these bands can be assigned definitely to various trapping centres, although I have made some tentative assignment from the study of glass systems of different composition.

Department of Chemistry,

SADHAN BASU

University of Calcutte,

92 Upper Circular Road, Calcutta 9.

\section{Reproduction of Potato Root Eelworm during the Winter in a Potato Clamp}

Is early March 1955, a freshly opened clamp of King Edward potatoes was inspected at Little Downham, Isle of Ely. It was observed that cysts of potato root eelworm (Heterodera rostochiensis) had already formed on the roots of many tubers which had sprouted and grown in the clamp. The cysts were in various stages of development. Some were white and others had turned yellow and contained fully embryonated eggs. It was estimated that there were more than a hundred cysts on some root systems. The wet autumn of 1954 had made lifting conditions very difficult and much damp soil had been clamped with the potatoes. Under these conditions root growth had been induced, and it is certain that the larvæ must have invaded the roots within the clamp and completed their development during the winter.

The field, on the black fen, was sampled to determine the level of infestation. The infestation was severe-5.24 viable cysts per gm. and 1,072 eggs per gm. of air-dried soil.

When a fiold is lightly infested with potato root eelworm, the clamp site will quickly become contaminated, as some soil will be deposited there from all parts of the field during harvesting operations. In addition, a clamp site often supports a high population of volunteer potatoes which will help to build up the eelworm numbers. If reproduction occurs within the clamp, the level of infestation may be increased still further, even though it is possible that many larva do not reach maturity under these conditions.

National Agricultural Advisory Service,

T. J. LEGOWSKI

E. B. Brown

Anstey Hall,

Trumpington, Cambridge.

Oct. 3.

\section{Migration of Nematodes}

THE relationship between hydrostatic pressuredeficiency and the migration of larvæ of the beet eelworm, Heterodera schachtii Schmidt, has been described previously ${ }^{1}$. It was shown that larval mobility was low in sand in which water was con. fined to the points of contact of sand particles. It was suggested that more critical experiments would be needed to determine whether there was an optimum pressure-deficiency for eelworm migration.

Accordingly, an apparatus (Fig. 1) was devised for examining this problem further, using the stem eelworm Ditylenchus dipsaci. $a-b$ is polythene tubing,

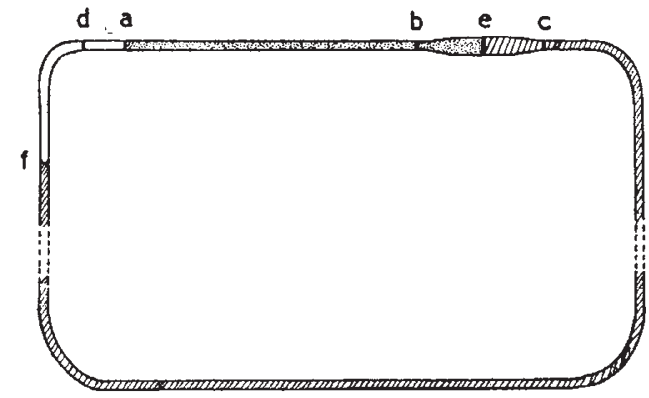

Fig. 1 